\section{Conflito de deveres do médico de saúde ocupacional face à entidade patronal no Brasil}

\section{The conflict of duties of the occupational health physician in Brazil}

João Pereira Ramos 1

\begin{abstract}
The article reflects on the ethics and bioethics of the work of the occupational health physician. Whatever branch of medicine, the work involves health, sickness and patients, and collective and individual analyses. It is the role of the physician to work on occupational health in the workplace. Occupational medicine exists because health is an indispensible civil right. Companies thus hire doctors to take care of the health of their employees, primarily so as not to infringe existing laws and, secondarily, to increase their profit by expanding production and the work of healthy individuals. This involves conflicts between the duties of the physician and the interests of the company. The physician, however, in this peculiar situation, should abide by ethical and bioethical principles.
\end{abstract}

Key words Bioethics, Occupational medicine, Conflict, Occupational health
1 Programa de Doutoramento em Bioética. Faculdade de Medicina. Universidade do Porto. Alameda Prof. Hernâni Monteiro, 4200319. Porto, Portugal. E-mail: jramos3@uol.com.br

\section{Resumo}

O artigo faz reflexão ética e bioética da atuação do médico enquanto profissional de saúde ocupacional. Seja qual for o ramo da medicina ela estará abordando: saúde, doença e doente, cabendo análises individuais ou coletivas. É função do médico trabalhar a saúde ocupacional dentro da empresa. A medicina do trabalho existe pelo fato da saúde ser um direito imprescíndivel ao cidadão. Nesta perspectiva, os sistemas empresariais contratam médicos para cuidarem da saúde de seus trabalhadores, primeiro para não infrigirem leis vigentes segundo, aumentar o lucro através do acréscimo de produções ou trabalho das pessoas saudáveis. Nestes aspectos enumeram-se conflitos de deveres do médico e de interesses da empresa para qual trabalha. O médico contudo, mesmo em situação peculiar deverá manter a observância de princípios éticos e bioéticos.

Palavras-chave Bioética, Medicina do trabalho, Conflito, Saúde ocupacional 


\section{Introdução}

Falar em conflitos, logo se remete a ideia de uma situação constrangedora e complexa. Por vezes é o que acontece com os médicos, eles enfrentam circunstâncias de controvérsias morais e de valores defendidos por estes profissionais no ato da sua prática. Esta situação é comum na relação entre os interesses da empresa e o do profissional da medicina do trabalho.

Assim, percebe-se que há conflitos no ato da prática dos deveres do médico e a concepção estratégica existente tanto da empresa quanto do profissional da medicina na contemplação de convenção do meio social. Enquanto a empresa busca lucratividade por meio das transações comerciais e o segundo anseia pela vitalidade humana ou a cura das enfermidades dos pacientes. Noutras palavras, ambos buscam atender às suas demandas ou necessidades próprias. Visto que o sistema empresarial busca ampliar a desenvoltura de suas negociações de maneira organizada e sistematizada e os médicos cumprir com seus valores éticos e morais em prol da vida humana.

Para melhor compreender esta relação de empregador/empregado é importante conhecer a origem das empresas e depois a relação desta com as pessoas, por meio da administração. Ressalta-se que os sistemas empresariais tiveram início com os muçulmanos. Para Cavalcanti ${ }^{1}$ as primeiras iniciativas atribuídas às formações do que hoje denominamos empresas tiveram seus esboços na era medieval no mundo muçulmano. Empreendedores cristãos teriam mais tarde levado adiante e aprimorado este modelo, sendo que posteriormente o rei inglês Eduardo I (1272-1307), com o Estatuto da Mão Morta, promoveu as ações propiciando progressões e aprimoramento até o perfil corporativo atual.

Então, a idéia de empresa é antiga, mas seus avanços são impressionantes em todos estes anos e séculos. Visto que hoje as mesmas se diferem até em suas tipologias, como em: micros, médias e macros, ou seja, essas classificações mudam de acordo com o valor patrimonial. Segundo Mosimann ${ }^{2}$ podemos entender como empresa ao conglomerado humano com criação por indivíduo único ou múltiplos (sócios), organizado, adotando uma hierarquia para administrar ações intelectuais, físicas e financeiras com fins de extrair, transformar, transportar e distribuir riquezas ou produzir serviços.

Podemos dizer que este agrupamento é a mola propulsora da desenvoltura econômica do meio social, por articular toda a engrenagem financeira, onde as pequenas empresas sempre exerceram e desenvolveram um papel importantíssimo na economia do país. Estas se constituem pelas aglomerações de pessoas, ou seja, as mesmas formam o ambiente empresa a qual varia em quantidade de acordo com a sistematização e diversidade que por sua vez traz nomes e definições distintas, tais como micro ou pequenas e médio porte, e contratam funcionários de acordo com a sua produtividade. Coelho ${ }^{3}$ as conceitua como: micro empresa, pequena empresa e indústria, conforme a quantidade de pessoas ocupadas.

Nesta perspectiva as empresas são constituídas e conceituadas como atividades e marcas essenciais para as obtenções de lucros, as quais são oferecidas ao mercado de bens ou serviços, que por sua vez são gerados mediante a organização dos fatores de produção da força de trabalho, matéria-prima, capitais e tecnologias.

Em suma a empresa só pode ser compreendida como uma atividade econômica quando revestida em duas qualidades: economia e sistematização. Os fundamentos organizacionais que envolvem atos civis e mercantis é o que gera o objeto de estudo teórico para implementação de novos paradigmas de gerenciamentos empresariais. Assim, a concepção de uma entidade, seja ela grande, média ou pequena, com ou sem fins lucrativos, não se torna possível sem a adoção de uma série de princípios teóricos administrativos que irão engendrar a organização e a consequente desenvoltura empresarial.

Para Franco 4 as empresas são entidades com fins econômicos, objetivando sempre o lucro. Se observa que o complexo chamado empresa constitui-se pelas operações comerciais de compra e venda de produtos ou prestação de serviços. Essa transação de compra e venda caracterizará a receita e despesa da entidade e demonstrará a movimentação patrimonial apresentando seu crescimento ou redução.

Credita-se ao sistema empresarial o desenvolvimento econômico das nações. Sua desenvoltura é de responsabilidade do patrimônio intelectual constituído pelas pessoas, motivos de muitas discussões em vários setores da sociedade, dentre eles destacase a saúde que por sua vez é representada por vários profissionais de inúmeras ramificações, especialmente da medicina.

\section{Médico do trabalho e sua função na empresa}

Médicos do trabalho exercem papel fundamental na mediação entre empregado e empregador no que diz respeito ao exercício da objetividade desta profissão 
que é de conhecer os enfermos e as suas doenças; estudar, ampliar, executar e criar novas metodologias de trabalho para proporcionar bem-estar físico, social, psíquico e mental; pesquisar para obtenção de avanços no conhecimento e assim melhorar nos possíveis diagnósticos; possibilitar dias melhores para quem sofre com doenças crônicas ou incuráveis, além de avaliar a sua própria atuação.

E ainda atender às demandas da empresa que podem advir de desdobramentos sob vários aspectos éticos próprios da relação do quadrinômio: empresário, empresa, medicina ocupacional e empregados que podem gerar conflitos de interesses e de deveres, alem de responsabilidades com repercussões de valores éticos ou bioéticos consideráveis. Não se concebe ao médico do trabalho (medicina ocupacional) esquivar-se de atentar à observância de princípios bioéticos na execução de seus atos.

\section{Medicina ocupacional e ética}

No ambiente circunscrito de uma empresa seja qual for seu porte, seu ramo de atividade, haverá sempre a hipótese que no exercício de sua função social existam possibilidades reais de que seus funcionários diretos e ou indiretos possam correr riscos de contraírem doenças, sejam por acidentes, sejam por exposições a situações diversas, sejam por múltiplos outros fatores, o que comprometerá o trabalho e a realização de atividades eficazes ou de transformação do meio social almejada pelo empreendedor. Por esta razão e seguindo determinações legais os empresários são obrigados criarem serviço de medicina ocupacional para prevenir doenças, manter a saúde e restabelecer a segurança do trabalhador. Não haverá progresso empresarial sem atenção e valorização da matéria prima "colaboradorfuncionário". Rolo 5 acredita que as indústrias modernas tanto trazem grandes progressos sociais, como também ampliam índices de doenças em quantidade e em tipologia, ou seja trazem vantagens e desvantagens. Isto obriga as empresas a repensarem questões éticas, morais além pensar a saúde individual e coletiva funcional

Pensar a saúde na sua globalidade é refletir sobre o homem como um universo complexo, constituído pelo físico, psicológico e social. As empresas necessitam de médicos que auxiliem na permanência das pessoas na desenvoltura dos trabalhos através do cuidado na execução dos serviços, visto que estes devem manter o equilíbrio físico, psicológico e psicossociológico.

Destarte, a medicina do trabalho é fundamental na empresa quando trabalha o homem como um todo desde a estrutura fisíca até a relação deste com os seus semelhantes, o que por sua vez requer ética médica. Cada um destes trabalhadores apresentam um tipo de diagnóstico, que numa visão bioética, terá restabelecido o sigilo, o respeito à sua autonomia mantendo sua integridade moral e social. Em outras palavras, a bioética é o valor ético enquanto integração do homem a sua própria dignidade no que se relaciona a necessidade de responsabilidade e tolerância para a vida em sociedade. Deste modo, conceitos bioéticos aplicados nas empresas através da medicina do trabalho, fazem a conexão entre empresa/empregador/empregado com o escopo de avaliar os riscos ou os males que o trabalho pode trazer aos funcionários, sendo que esta prática médica deve vir sempre acompanhada com a intenção de beneficiar e nunca de prejudicar.

Monte 6 é bem enfático ao defender que a prática médica deve beneficiar sempre, embora que possa haver o risco de vir a prejudicar, há que perseguir-se ao beneficio não permitindo o oposto. $\mathrm{O}$ ato médico, por muitas vezes, assume conduta com a conotação "prejudicar" para beneficiar. Como se sabe há muitas pessoas que já precisaram perder membros ou partes importantes do corpo para continuar sobrevivendo. Por exemplo, uma pessoa com um pé diabético em necrose avançada, onde o médico assistente, consciente ou não dos princípios bioéticos da beneficência e não maleficência, assume uma postura com resultado predominantemente benéfico para a saúde e bem-estar do paciente, optando por amputar o pé. O paciente fica curado porém com um membro mutilado. Assim, tal situação consiste em exemplificar que a ética está presente em atos médicos aparentemente prejudiciais, vez que estes são benéficos, são feitos por estarem corretos numa concepção bioética, buscando desempenhar seu papel enquanto atividade de justiça, de respeito ao espaço do outro, de igualdade de direitos assumindo a aplicabilidade da arte de relacionar entre os componentes de um determinado convívio humano.

Chalita ${ }^{7}$ advoga que pessoas justas se sentem bem quando conseguem se manter como tal em meio à injustiça. Defende ser mais importante do que implantar uma sociedade perfeita, é viver em meio de erros e consequir corrigir injustiças neste ambiente social. Lembra ainda que a justiça deriva das atividades humanas e são cultivadas no coração e nas regras impostas de convivência.

Percebe-se assim que a ética da medicina do trabalho funciona, com escopo de beneficiar tanto aos seus próprios critérios quanto aos da empresa para com os seus trabalhadores. A discussão e 
concepção bioética ainda emergente pela sua própria condição de recenticidade, cresce do interesse de preservar valores humanos enquanto seres sociáveis.

\section{A bioética}

Numa concepção generalizada e sucinta pode ser defendida como toda forma de ética aplicada à vida. Este entendimento de ética é intimamente correlacionado ao conceito de moral devendo traduzir-se nos comportamentos dos sujeitos no exercício das várias ciências, das artes, e de todas as atividades e tomadas de decisões envolvendo interesses da humanidade. Seja da pesquisa científica conduzida pelo mais renomado cientista ao simples exercício médico num consultório de medicina do trabalho.

Analisando-se o vocábulo bioética morfologicamente e semanticamente percebe-se que o mesmo deriva do idioma grego, dividido em duas partes, são elas: "bios" que significa "vida" e "ethike" que significa "ética", em outras palavras este neologismo significa elaborar cuidados que ampliem o zelo legal pela vida humana, aonde profissionais, médicos por exemplo, devem usar seus conhecimentos científicos dentro dos princípios éticos para ajudar no usufruto da saúde, principalmente quando o atendimento abrange as questões sociais.

Deste modo, mostra que a bioética é mais ampla que a ética médica tradicional, visto que a primeira abrange a relação da medicina e outras áreas da saúde com as questões sociais e a segunda se restringe apenas a relação médico-paciente e com seus colegas de profissão.

A bioética é a ética utilizada pela medicina que vai além da relação médico/paciente e comunidade, ocupando-se especialmente dos problemas relacionados aos cuidados da saúde e da vida. Relaciona-se a todos os problemas éticos no que diz respeito ao cuidado da vida e da saúde dos homens e mulheres numa determinada sociedade.

Plausível, portanto, compreender que a bioética é a ética utilizada pela medicina enquanto ciência que beneficia o homem na saúde, sistematizando a prática legal entre médico e paciente. Em outras palavras, é um tipo de convenção feita entre a ciência e o homem para dar respaldo de seriedade, respeito e qualidade a vida humana.

A bioética tem como função e objetividade defender a oferta da saúde com qualidade aos sujeitos, atendendo suas necessidades, já que é um direito prescrito na legislação brasileira ou na Constituição Federal de $1988^{8}$ em seu Art. 196, diz: "a saúde é direito de todos e dever do estado", noutras palavras o homem tem direito de receber cuidados especiais para a cura de suas enfermidades, o que respectivamente possibilita melhor qualidade de vida. Quanto à obrigação do estado em oferecer condições de tratamento deriva do conceito de uma sociedade democrática, onde se pressupõe que todos têm o mesmo direito diante da lei como descreve o Art. $5^{\circ}$ desta mesma Constituição.

Neste contexto a bioética é um instrumento que serve como mediação de diálogo entre o médico e o enfermo, no que diz respeito às doenças e os possíveis conflitos morais que esta relação possa trazer. Para Braga, ${ }^{9}$ a bioética é um campo disciplinar decorrente da necessidade de se lidar com os conflitos morais, quando presentes, nos processos de interações profissionais e pessoais envolvendo saúde e doença.

Para a autora esta ciência, no tocante à medicina, pode ser vista de certa forma como uma disciplina de princípios norteadores do comportamento médico nos seus procedimentos ou práticas, os quais não podem violar os direitos de seus pacientes em situações como: quebrar sigilo sem uma justificativa de beneficio; utilizar-se de seus conhecimentos para gerar sofrimento físico ou moral ou para a exterminação do ser humano; ou ainda, permitir atos injustos contra a dignidade e integridade do sujeito.

\section{A bioética e a medicina do trabalho}

A medicina do trabalho baseia-se nas vertentes: as avaliações individual e coletiva dos trabalhadores no que diz respeito ao diagnóstico e ao controle clínico e aos riscos das ocorrências ocupacionais e acidentárias do trabalho no âmbito das empresas.

Pressupõe-se que esta medicina estuda, previne e trata os males das doenças derivadas do trabalho e ou seu ambiente, ou seja, este profissional analisa a saúde e doença das pessoas enquanto prejuízo pessoal e coletivo, e ainda as possíveis ameaças e agravos que estas podem ocasionar nas relações entre os trabalhadores dentro de um estabelecimento comercial ou empresarial. Sendo que este trabalho depende de instrumentos técnicos e do relacionamento humano e ético.

Pode-se dizer, que a medicina do trabalho é uma das metodologias de se trabalhar a saúde no meio social com finalidades diferentes, mas com o mesmo objetivo que é de cuidar e zelar de vidas humanas. Como preceitua Souto (2005: 15 )10 "A medicina do trabalho está fundamentada na ciência e deve recorrer a comprovadas tecnologias disponíveis como instrumentos de trabalho, além disso, envolve aspectos de relacionamento humano, ético, jurídico trabalhista e previdenciário". 
De um modo geral a ética é o princípio de organização, de ordem na vida de qualquer sujeito, assim sendo o médico utiliza-se da mesma para proteger e cuidar de vidas, que em sua maioria se encontra em situações de saúde que devem ser omitidas ao conhecimento de outras pessoas, o que por sua vez se traduz em sigilo médico. Mas, em alguns casos não há como ocultar por se considerar direitos iguais para todos. É comprensível que tanto o doente quanto os colegas de trabalho, por exemplo, têm direito de serem informados dos riscos de doenças a que estão expostos.

A quebra de sigilo em algumas circunstâncias é necessária, embora a obediência às regras éticas são tidas como leis e quem as desobedece é considerado infrator. Contudo, existem situações em que este sigilo deve ser desconsiderado pela prática médica em benefício do bem comum, por exemplo, quando a doença de um funcionário da empresa põe em risco a saúde de todos os outros, e medidas assim devem ser implementadas para que seja respeitado o direito à saúde destes outros indivíduos, bem como manter o ambiente da forma mais saúdavel possível. E de acordo com o Conselho Federal de Medicina do Brasil (CFM) n 1.246/88:11 "O médico deve manter sigilo quanto às informações confidenciais de que tiver conhecimento no desempenho de suas funções. O mesmo se aplica ao trabalho em empresas, exceto nos casos em que seu silêncio prejudique ou ponha em risco a saúde do trabalhador ou da comunidade".

\section{Deveres do médico de saúde ocupacional e do} empresário como respeito à dignidade humana

Como todo trabalhador, o médico do trabalho também é dotado de direitos e deveres. Aqui serão destacadas as suas obrigações para com a vida dos funcionários da empresa em que trabalha, orientando-os dos perigos ou riscos que o trabalho proporcionará no decorrer do tempo. Fornecer subsídios para que os empresários (patrões) tornem-se conscientes: dos possíveis riscos que o desempenho das atividades funcionais da empresa pode causar à saúde dos seus funcionários; da adoção de políticas preventivas de riscos inerentes ao trabalho; e da manutenção de profissionais que implantarão um programa de controle médico de saúde ocupacional (PCSMO) da empresa, conforme preceitua a legislação. ${ }^{12}$

As observâncias legais não se restringem apenas às relações interpessoais de empregador e empregado, vão além conforme prescreve a Lei $\mathrm{n}^{\circ}$ 6.514/77 de 22 de Dezembro de 1977:13 “Art. 160 Nenhum estabelecimento poderá iniciar suas ativi- dades sem prévia inspeção e aprovação das respectivas instalações pela autoridade regional competente em matéria de segurança e medicina do trabalho".

Nestes termos percebe-se que as empresas para funcionarem de acordo com o Ministério do Trabalho necessitam viabilizar várias ações, por exemplo: manter ativa uma CIPA (Comissão Interna de Prevenção de Acidentes), oferecer materiais de proteção individual e coletiva gratuita, realizar exames médicos e enfim um trabalho minucioso com a gestão de pessoas.

A Lei $\mathrm{n}^{\circ}$ 6.514/7713 diz ainda em seus Art. 162, 163,166 e 168 que:

\footnotetext{
"as empresas, de acordo com normas a serem expedidas pelo Ministério do Trabalho, estarão obrigadas a manter serviços especializados em segurança e em medicina do trabalho. E que será obrigatória à constituição da Comissão Interna de Prevenção de Acidentes (CIPA), em conformidade com instruções expedidas pelo Ministério do Trabalho, nos estabelecimento ou locais de obra nelas especificadas. Lembrando que a empresa é obrigada a fornecer aos empregados, gratuitamente, equipamento de proteção individual adequado ao risco e em perfeito estado de conservação e funcionamento, sempre que as medidas de ordem geral não ofereçam completa proteção contra os riscos de acidentes e danos à saúde dos empregados. E ainda esta tem obrigação de proporcionar o exame médico dos funcionários nas condições estabelecidas e expedidas pelo Ministério do Trabalho".
}

Sabendo que os cuidados médicos são voltados para o diagnóstico e prevenção da saúde do trabalhador, com intuito de atender dois interesses básicos, sendo o primeiro a valorização da vida humana e o segundo como proteção ao instrumento de produção e lucratividade da empresa. O último por sua vez provoca discussões polêmicas, verdadeiros conflitos de idéias e interesses entre recursos financeiros e valores humanos. Assim, às vezes, o médico do trabalho precisa atentar para uma visão bioeticamente aceitável de forma que como fiel da balança entre o empregado e empregador deve atuar de forma concisa deixando o mínimo de arestas que possam ferir o respeito e dignidade ao homem e a mulher em meio a sociedade, ao mesmo tempo que cumprirá seu papel de também empregado da empresa. Ressalta Haase (2007: 118):14 "A bioética surge na metade do século XX como resultado da indignação moral provocada por diversos crimes hediondos, tais como: experiências médicas na Alemanha nazista. A bioética se articulou em torno de quatro princípios genéricos: o respeito à 
pessoa humana, a beneficência, a justiça e a não maleficencia".

Nesta perspectiva o médico como profissional praticante destes princípios precisa e deve respeitar, fazer o bem e ser justo com seu paciente em qualquer circunstância.

\section{Bioética: contexto Brasil}

A bioética como sendo um conceito novo, firmandose nas últimas décadas no meio científico e nas sociedades, encontra-se em nosso meio em fase de crescimento, estando em expansão e influência ainda lenta e inferior a países da União Européia e Estados Unidos. Chegou mais ou menos duas décadas mais tarde. Ainda está amadurecendo por meio dos vários estudos. Segundo Braga ${ }^{9}$ a bioética brasileira pode ser considerada tardia e tem grande influência do pensamento americano, porém mesmo sendo esta uma referência mundial, há de considerar-se que os modelos bioéticos não se aplicam universalmente em todos os países sem que sejam observadas as peculiaridades culturais de cada um. Para esta autora a bioética no Brasil esta em fase de amadurecimento.

Acredita-se que os estudos podem servir de ponto de partida para o desenvolvimento da ética dos médicos para com os pacientes, especialmente na saúde pública ou atendimento feito pelo SUS, programa que possibilita o direito a saúde gratuita. E que a medicina não pode deixar seus princípios, em prol do paciente e assim por diante. Monte 6 propõe uma forma tríade de análise dos aspectos éticos na prática médica composta pela relação médico/ paciente; médicos/médicos e médicos/sociedade.
Sendo que este tripé é um conjunto de valores da profissão com o sujeito atendido e o meio no qual este profissional atua.

\section{Considerações finais}

Este estudo faz uma análise preceituando a bioética como a convenção de respeito a dignidade e aos valores humanos, que além de valorizar especialmente os direitos a saúde, estabelece conflitos de deveres na prática médica no âmbito das empresas (saúde ocupacional). Há situações frequentes onde os interesses da empresa, com suas demandas e exigências, entram em conflito de deveres do médico do trabalho. Este, mesmo na condição de empregado, é ao mesmo tempo detentor de autonomia profissional e preso a normativos éticos a serem preservados, ainda que contrariando a hierarguia empresarial.

A segurança em medicina do trabalho constituise em normatizações humanizadoras visando o bemestar de pessoas na prestação de serviços às empresas, onde estas estão submetidas aos riscos de acidentes e agravos, virtuais atributos deletérios a saúde dos trabalhadores. A imperiosa necessidade da empresa adotar requisitos e postulados designados pela legislação pertinente pressupõe o restabelecimento de estado de respeito a dignidade humana.

Assim, a bioética opera com os conflitos da moral humana que por sua vez são convenções desta tão recente ciência que possibilita plena execução e vivência dos direitos na saúde, especificamente na medicina do trabalho no interior das empresas.

\section{Referências}

1. Cavalcanti CA. Como Surgiram as Empresas? Disponível desde 15/04/2009 no <http://desafio21.informazione2. com.br:8080/cms/opencms/desafio21/artigosgestão/planejamento/0022.html>

2. Mosimann CP. Controladoria: seu papel na administração de empresas. 2 ed. São Paulo: Atlas; 2008. 138p.

3. Coelho PCA. Fatores gerenciais que influenciaram na mortalidade das micro e pequenas empresas: um estudo sobre a mortalidade das empresas comerciais de Manaus entre 1995 e 1997. Florianópolis: Insular; 2001.

4. Franco H. Contabilidade Geral. 22 ed. São Paulo: Atlas; 2008

5. Rolo JC. Sociologia da saúde e da segurança no trabalho. IV Congresso Português de Sociologia. Disponível em:< htttp://www.aps.pt/cms/docs/DPR462e09d50c3e5 1.PDF>

6. Monte FQ. A ética na prática médica. Rev Bioética. 2002 2: 32-46.

7. Chalita G. Os dez mandamentos da ética. 1 ed. São Paulo: Nova Fronteira; 2003.

8. Brasil. Constituição (1988). Constituição da República Federativa do Brasil: texto consolidado até a emenda constitucional de 23 de setembro de 2009. Disponível em: $<$ http://www.senado.gov.br/sf/legislacao/const/>.

9. Braga KS. Bioética Brasileira: 1990-2002. Brasília: Letras Livres; 2002. 296 p.

10. Souto DF. Organizado pela Câmara Técnica de Medicina do Trabalho e Saúde do Trabalhador do CREMERJ. Rio de Janeiro: CREMERJ; 2005.

11. Brasil. Conselho Federal de Medicina. Resolução $\mathrm{n}^{\circ}$ 1246/88. Código de Ética Médica. Brasília, DF; 1996.

12. Brasil. Lei $n^{\circ} 6.514$, de 22 de dezembro de 1977. NR-7 In: Segurança e Medicina do Trabalho. 62 ed. São Paulo: Atlas S.A; 2008. p. 81-93. 
13. Brasil. Lei $\mathrm{n}^{\circ} 6.514$, de 22 de dezembro de 1977. Segurança e Medicina do Trabalho. 62 ed. São Paulo: Atlas S.A; 2008. p. 2-3.

Recebido em 29 de junho de 2010

Versão final apresentada em 20 de setembro de 2010

Aprovado em 22 de novembro de 2010
14. Haase GV. Neuropsicologia e autonomia decisória: implicações para o consentimento informado. Rev Bioética.2007; 15: p.117-32 